GLOBAL DEVELOPMENT AND ENVIRONMENT INSTITUTE

WORKINg PAPER No. 06-07

\title{
The Economics of Inaction on Climate Change: A Sensitivity Analysis
}

\author{
Frank Ackerman and Ian J. Finlayson
}

October 2006

\author{
Tufts University \\ Medford MA 02155, USA \\ http://ase.tufts.edu/gdae
}




\title{
The Economics of Inaction on Climate Change: A Sensitivity Analysis
}

\author{
Frank Ackerman and Ian J. Finlayson
}

\begin{abstract}
Economic models of climate change often take the problem seriously, but paradoxically conclude that the optimal policy is to do almost nothing about it. We explore this paradox as seen in the widely used DICE model. Three aspects of that model, involving the discount rate, the assumed benefits of moderate warming, and the treatment of the latest climate science, are sufficient to explain the timidity of the model's optimal policy recommendation. With modifications to those three points, DICE shows that the optimal policy is a much higher and rapidly rising marginal carbon price; that higher carbon price has a greater effect on physical measures of climate impacts. Our modifications exhibit nonlinear interactions; at least at low discount rates, there is synergy between individual changes to the model. At low discount rates, the inherent uncertainty about future damages looms larger in the analysis, rendering long-run economic modeling less useful.

Our analysis highlights the sensitivity of the model to three debatable assumptions; it does not, and could not, lead to a more reliably "optimal" cost of carbon. Cost-effectiveness analysis, focusing on the generally shorter-term cost side of the problem, reduces the economic paradoxes of the long run, and may make a greater contribution than economic optimization modeling.
\end{abstract}

\section{Introduction}

How much should be done to respond to the threat of climate change? As the scientific understanding of the threat becomes increasingly powerful and detailed, and the few remaining skeptics fade into obscurity, many people naturally conclude that vigorous action is needed. Much of the discussion of policy initiatives involves technology and diplomacy: what is it technically possible to do? And, since the problem is global in scope, what can all or most of the world agree to do?

Economists frequently address climate change in a very different mode, attempting to weigh the costs and benefits of alternative policies and thereby calculate the optimal policy response. This calculation often leads to the conclusion that relatively little should be done for now. Unlike the climate skeptics, economic modelers rely on the mainstream understanding of climate science; this makes their recommendation of short- 
run inaction all the more surprising and challenging, for those who are inclined toward immediate action.

In this paper we explore the logic of the economic argument for inaction on climate change, as seen in the DICE model. DICE, created by William Nordhaus, is the simplest and probably the most widely used of the major economic models. We make three modifications to DICE, involving lower discount rates, reconsideration of the assumed subjective benefits of moderate warming, and updates to the technical parameters representing climate dynamics. The influence of the discount rate is wellknown, although debate continues about the nature of the problem and the appropriate remedy. The crucial assumption about the subjective benefits of warming, on the other hand, has received relatively little attention. Moreover, it turns out that our three modifications to DICE are synergistic, with nonlinear, cumulative impacts on the model results.

Section 2 briefly describes the DICE model, and sections 3-5 present and motivate our three modifications. Results for the modified versions of the model are presented in section 6 , followed by conclusions in section 7 .

\section{The DICE model}

DICE is an acronym for Dynamic Integrated model of Climate and the Economy. It combines a simple macroeconomic growth model with a basic representation of the dynamics of carbon emissions, atmospheric concentrations, and expected temperature increase. (Nordhaus 1999; Nordhaus and Boyer 2000) The admirable decision by Nordhaus to make DICE freely available for downloading on his web site has turned it into a de facto open-source standard for economic modeling of climate change policy.

In DICE, fossil fuels are one of the inputs into production, giving rise to $\mathrm{CO} 2$ emissions to the atmosphere. In a three chamber physical model, the atmosphere mixes quickly with the upper oceans and biosphere, and slowly with the deep oceans. Rising atmospheric concentration of carbon leads to radiative forcing, and thus to temperature increases. To close the loop, the rising temperature makes the economy less efficient: economic damages, modeled as reductions in output for any given inputs, start small but worsen with rising temperatures. There is also a risk of a larger, "catastrophic" loss of $30 \%$ of global output; the probability of this catastrophe is low, but increases with rising temperature.

The principal policy instrument in the model is a carbon tax, which raises costs but also lowers carbon emissions, eventually reducing temperature increases and future damages. Although DICE explicitly refers to carbon taxes, its treatment of public policy is quite abstract; there is nothing in the model that requires the cost of carbon to be expressed via taxation. Any other policy instrument expressing and internalizing the same social cost of carbon, such as tradable permits, would have the same economic impacts and results. For compatibility with current policy discussion (e.g., (Watkiss 2005)), we 
will therefore refer to the model estimates as the price or cost of carbon. The objective of the model is to set the price of carbon to maximize the discounted present value of the future stream of consumption plus a few non-market amenities over the next several centuries; the Excel spreadsheet version of DICE runs for 340 years from its 1995 base year.

The basic DICE projection, labeled NB for Nordhaus-Boyer in our discussion below, finds that the optimal carbon price is less than $\$ 6$ per ton in 1995, and less than $\$ 10$ per ton in 2005 , rising very gradually to only $\$ 140$ per ton in 2195 , some 200 years into the simulation. (All monetary amounts are in 1995 US dollars. Our decision to focus on projections for 2195 is explained in the appendix.) The slightly decreased emissions that result from internalizing this carbon price cause a temperature decrease of only $0.2^{\circ} \mathrm{C}$ by 2195 , compared to the business as usual scenario.

Hence the paradox that motivates this paper: DICE offers a well-known, accessible tool for analysis of climate change (within the framework and limitations of neoclassical economics); its creators clearly understand the seriousness of the problem, and have put real effort into representing climate dynamics in the model. And yet they calculate that the optimal policy is to do so little that future temperature increases are barely affected. Is this a deep truth about the economics of climate change, or an artifact of particular modeling choices and assumptions embodied in DICE? Our answer will be the latter: we will demonstrate that a dramatically different policy recommendation results from just three plausible modifications to the model, involving the discount rate, the description of climate dynamics, and the benefits of moderate warming.

We are not the first to explore the sensitivity of DICE to minor modifications. The importance of the discount rate, in particular, has been documented both in Nordhaus' own work and in independent research (Schultz and Kasting 1997). Other researchers have studied the effects of improvements in the DICE treatment of the carbon cycle (Joos et al. 1999), and the impact of uncertain climate thresholds for small but irreversible losses (Keller et al. 2004). A recent analysis argues that DICE and similar models cannot adequately reflect the risks of abrupt, catastrophic climate change (Hall and Behl 2006). (If it occurred today, the potential "catastrophe" modeled by Nordhaus and Boyer, a 30\% loss of output, would amount to a return to the per capita income levels of the $1980 \mathrm{~s}$ or 1990s for many countries. This seems rather milder than the potential catastrophes analyzed by many climate scientists.)

The closest to our own approach is the analysis by William Cline, who has made multiple modifications to the DICE model and finds that the modified model supports vigorous action on climate policy (Cline 2004). In fact, one of our three modifications is taken directly from Cline's analysis. We differ from Cline in taking a different approach to the discount rate; in examining the subjective benefits of warming, a topic which he omits; and in focusing on the nonlinearity of interactions among the various modifications. 


\section{Discounting}

The best-known piece of the puzzle about the economics of climate change is the choice of the discount rate: high or even moderate rates seem to imply that even extreme far-future outcomes don't matter much to the present generation. US government agencies frequently use discount rates of 3\% and 7\% as high and low cases for evaluation of future benefits. A benefit of $\$ 1$ million, occurring 200 years from now, has a present value of about $\$ 2700$ at a $3 \%$ discount rate, and just $\$ 1.33$ at $7 \%$. Thus unless the discount rate is very low, the benefits of climate change mitigation in future centuries are almost worthless in present value terms, and any significant short-term expenditures are "too expensive" relative to their (present value) benefits.

This paradox of discounting is only one of the difficulties in the economic analysis of the very long run. Rigorous analysis shows that economic models spanning many generations are frequently indeterminate, with opportunities for multiple equilibria and chaotic dynamics (DeCanio 2003, Chapter 3). More than just efficiency and optimization is at stake: any approach to discounting has profound implications for equity, between generations and between rich and poor (Howarth and Norgaard 1992), (DeCanio and Niemann 2006). The environmental economics of the very long run remains an area of active theoretical debate; one provocative alternative suggests that not discounting but the substitutability between produced and environmental goods may be the source of the problem (Neumayer 1999).

Although the discounting problem is well-known, there is not yet a clear solution. Two major currents of discussion of long-run discounting, the distinction between prescriptive and descriptive approaches, and the more recent interest in variable rather than fixed discount rates, have thus far failed to resolve the dilemmas. We will review these issues, to motivate our alternative.

The extensive literature on discount rates distinguishes between "prescriptive" approaches, deducing the appropriate discount rate from first principles, and "descriptive" methods, using actual or anticipated market interest rates to determine the discount rate. The prescriptive approach builds on Frank Ramsey's classic analysis (Ramsey 1928). The "social rate of time preference," i.e. the discount rate applicable to long-term publicsector decisions, is the sum of two terms: the rate of pure time preference that would prevail if all generations were equally wealthy; and the effect of increasing incomes. Algebraically, the social rate of time preference, $r$, is given by

$$
\mathrm{r}=\rho+\theta \mathrm{g}
$$

where $\rho$ is the rate of pure time preference; $g$ is the growth rate of per capita consumption; and $\theta$, measuring the response of utility to a change in consumption, is often assumed to be either 1.0 or 1.5. (The limited, indirect evidence on the value of $\theta$ is discussed in (Ha-Duong and Treich 2004).) 
The idea behind the second term, $\theta \mathrm{g}$, is that the wealthier our descendents turn out to be, the less they will need help from us, and the greater the discount rate we should apply to their incomes. Note that if the growth rate, $g$, is expected to decline -- perhaps due to climate change or other environmental constraints -- then equation (1) projects a declining discount rate. In the extreme, if the economy contracts, so that the growth rate turns negative, it is possible for the discount rate to become zero or negative (Dasgupta et al. 1999). As a result, as Partha Dasgupta points out, differences in estimates of future climate damages, and hence future growth rates, can explain differences in the choice of the discount rate. Dasgupta suggests that Nordhaus, in particular, anticipates relatively limited damages from global warming, and therefore, following equation (1), uses a higher discount rate than others who anticipate greater damages and slower growth (Dasgupta 2001, 183-86).

Most of the debate concerns the first term, $\rho$, the discount rate that would apply if per capita consumption were constant. It has often been argued on philosophical grounds that $\rho$ should be zero. That is, the welfare of equally wealthy generations should be counted equally; from this perspective, the expected growth of incomes provides the only equitable grounds for discounting (Broome 1992). Cline, for example, maintains that $\rho$ is zero, $\theta$ is 1.5 , and $g$ will average $1 \%$ over the long run, implying that the appropriate discount rate is $1.5 \%$. Using this discount rate, he finds that cost-benefit analysis of climate change supports vigorous mitigation efforts (Cline 1992; 2004). Most economists working in this field, though, have argued that pure time preference should be positive; in theory, zero pure time preference could lead to implausibly high optimal rates of savings and sacrifice for the future (Arrow 1999).

While earlier writing by Nordhaus assumed a descriptive approach, the latest version of DICE introduces new behavioral assumptions, for an at least partially prescriptive approach. It assumes that the rate of pure time preference, $\rho$, begins at $3 \%$ and then very slowly declines, reaching $2.3 \%$ by 2100 and $1.8 \%$ in 2200 (Nordhaus and Boyer 2000, 15-16). It also implicitly assumes that $\theta$ is $1.0 .^{1}$

The descriptive approach, in contrast, bases the discount rate on market interest rates because those rates represent consumers' revealed preference for future versus present rewards (and also represent the opportunity cost of capital invested in climate change mitigation). It is common to conclude that the long-term average of the real rate of return on private capital is $5 \%$ or more. At discount rates that high, it is easy to show that only the most gradual reduction in emissions is "optimal" (Manne 1999).

Two important variants of the descriptive approach lead to lower discount rates. First, some authors have argued that the appropriate interest rate to use in discounting climate costs and benefits is the after-tax rate of return on risk-free investments, which is, on average, close to zero in real terms (Howarth 2003). Second, the appropriate interest rate for discounting purposes is the unknown future rate; averaging across multiple possible futures implies that the effective discount rate is steadily declining over time. If

\footnotetext{
${ }^{1}$ See the DICE99 Excel workbook, Model sheet, row 96, which uses a slightly different expression that is equivalent to equation (1) with $\theta=1$.
} 
there are several possible scenarios with different future interest rates, then the expected value of a future cost or benefit should be the average of the present value across all the scenarios. The farther one looks ahead, the more the scenarios with high interest rates have already discounted everything away to insignificance -- so that the average valuation is increasingly dominated by the low interest rate scenarios (Weitzman 1998), (Newell and Pizer 2004).

Both the prescriptive and descriptive approaches provide arguments for a declining, rather than constant, discount rate (Frederick et al. 2002). This alternative is often called "hyperbolic" discounting, since a graph of the discount rate, like a hyperbola, asymptomatically declines over time. Either declining future growth rates, in the prescriptive approach, or the analysis of future interest-rate uncertainty, in the descriptive approach, can lead to hyperbolic discounting. Geoffrey Heal has also demonstrated that a modified prescriptive model, incorporating a more nuanced, future-oriented view of human welfare and preferences, implies declining discount rates (Heal 1997). Hyperbolic discounting allows the economic analysis of short-term investments to proceed with little change, while the distant future is discounted less severely. David Pearce and his coauthors have suggested that this innovation solves the problem of dismissal of climate change and other far-future outcomes. (Pearce et al. 2003)

Unfortunately, the story is not that simple; hyperbolic discount rates can still lead to trivialization of the future. Nordhaus and Boyer use a time varying discount rate, assuming that $\rho$, the rate of pure time preference, begins at .03 and inches downward; both this and future declines in $\mathrm{g}$ can contribute to declining discount rates. But in practice, their variable discount rate doesn't matter. The rate is high enough in the first few decades to cause all far-future costs and benefits to be discounted away to insignificance.

This point is best illustrated by the discount factor -- the factor by which future values are multiplied to convert them to present values. For $n$ years at a fixed discount rate of $r$, the discount factor is $1 /(1+r)^{n}$. With a varying discount rate, $r_{t}$ in year $t$, the discount factor is the product of all the individual year factors $1 /\left(1+r_{t}\right)$. In the NordhausBoyer base case the discount factor is .16 in 2045 and .03 in 2095. That is, in the conversion to present value, future costs and benefits are marked down by $84 \%$ after 50 years, and by $97 \%$ after 100 years. The "hyperbolic" pattern of discount rates after 2095 only affects how fast the remaining $3 \%$ of value vanishes.

So it is not just the eventual decline in the discount rate that matters; much more important is how high it starts. The devil is in the details, and in this case the details that matter occur in the short run.

Our alternative is to set $\rho$, the rate of pure time preference, to zero, but otherwise to leave the DICE treatment of discounting unchanged. Under this assumption, the social rate of time preference reflects only the wealth effect: if all generations were equally wealthy, the discount rate would be zero. In our results, below, we refer to this modification as $\mathrm{S}$, for social rate of time preference. Figure 1 contrasts the discount 
factors implied by the Nordhaus-Boyer base case (NB), Cline's constant $1.5 \%$ discount rate, and our alternative $(\mathrm{S})$.

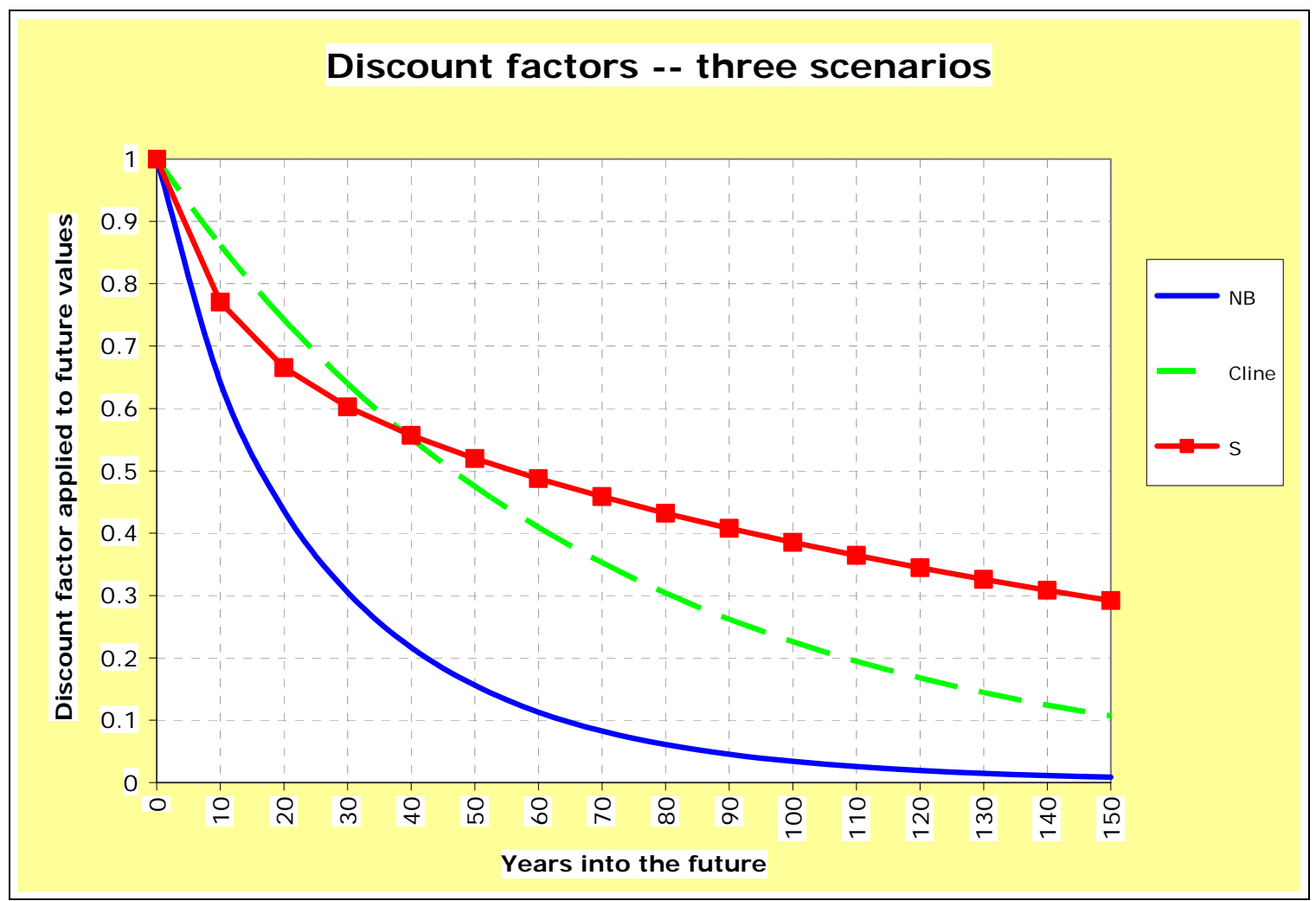

Figure 1

\section{Utility of moderate warming}

DICE calculates climate damages by estimating society's willingness to pay to avoid several types of consequences of increasing temperature, both marketed and nonmarketed (Nordhaus and Boyer 2000, 69-99). In addition to the monetary damages to agriculture, economic effects of sea-level rise, harm to other vulnerable market sectors, and the impacts of a low probability but moderately high-cost catastrophe, the calculations include three types of non-market values, which have been assigned monetary prices. Here we focus on the assumptions about non-market values.

The damages caused by climate change include numerous important but unpriced impacts, including loss of human life and health, harm to other species (including extinction in some cases), damage to fragile and irreplaceable ecosystems, and narrowing of the resource endowment and life choices available to future generations. A comprehensive cost-benefit analysis would have to include these factors -- but they are inherently priceless (Ackerman and Heinzerling 2004). The inevitably arbitrary choices about which unpriced impacts to include, and how to estimate their hypothetical 
monetary values, are frequently decisive to the outcome of a cost-benefit analysis. DICE is a case in point.

For two of its three non-market categories, DICE comes up with surprisingly small numbers. For health impacts of climate change, Nordhaus and Boyer offer a brief discussion of three ways of using one available database, resulting in a global estimate of $0.8 \%$ of GDP for the health damages caused by a $2.5^{\circ} \mathrm{C}$ warming. For the US, their estimate of health damages is much lower than the figures in the three other impact studies that they cite (Nordhaus and Boyer 2000, 97, Table 4.11).

The DICE estimates are even more minimalist for human settlements and natural ecosystems that are threatened by climate change. In the absence of any relevant data or detailed analyses, the authors arbitrarily assume that all climate-sensitive human and natural systems are worth only a fraction of one year's output (10\% of GDP, or $\$ 500$ billion in 1990, for the US). They then assume that people are willing to pay just $1 \%$ of that amount annually -- $\$ 5$ billion for the US -- to avoid all the human settlements and ecosystem damages caused by a $2.5^{\circ} \mathrm{C}$ warming. This implies an annual willingness to pay to avoid climate damages of almost $\$ 54$ per household, for the 93.3 million households in the US as of 1990. By way of comparison, studies conducted in the 1980s and early 1990s found an average annual willingness to pay for the protection of endangered species averaging $\$ 70$ per household for the Northern spotted owl, $\$ 63$ for Pacific salmon, and $\$ 46$ for grizzly bears (Loomis and White 1996). DICE thus assumes that people view global warming as a distinctly second-tier problem, a little more serious than the potential loss of grizzly bears, but less worrisome than the risk of losing spotted owls or Pacific salmon.

In contrast to the cautious treatment of health and ecosystem impacts, DICE becomes expansive when estimating the third non-market effect, the climate-related amenity value of leisure time. This is treated as a positive externality of climate change, at least until the world gets quite a bit hotter. The authors cite selected evidence about time use and temperature in the United States, from which they conclude that people enjoy warm weather outdoor recreation much more than cold weather activities. Specifically, they believe that the "positive amenity impact" of warming is maximized at a mean annual temperature of about $20^{\circ} \mathrm{C}$. This is roughly the temperature of Houston or New Orleans (cities where everyone who can afford it uses an air conditioner for much of the year); it is well above the current global average temperature of about $14.5^{\circ} \mathrm{C} .^{2}$ In a regional analysis, Nordhaus and Boyer conclude that a $2.5^{\circ} \mathrm{C}$ warming would be experienced as desirable in all major regions other than South Asia, the Middle East, and Africa. ${ }^{3}$

\footnotetext{
${ }^{2}$ The average temperature is $67.9^{\circ} \mathrm{F}$ in Houston and $68.1^{\circ} \mathrm{F}$ in New Orleans; $\underline{\text { http://www.cityrating.com }}$ $\left(68^{\circ} \mathrm{F}=20^{\circ} \mathrm{C}\right)$. The global mean temperature was $14.40^{\circ} \mathrm{C}$ in the $1990 \mathrm{~s}$, and $14.58^{\circ} \mathrm{C}$ in $2000-04$; Earth Policy Institute, "Global Temperature Rise Accelerating." http://www.heatisonline.org/contentserver/objecthandlers/index.cfm?id=4988\&method=full. ${ }^{3}$ Inferred from (Nordhaus and Boyer 2000) Table 4.10, page 91. The table includes "India" and "high income OPEC," which we have generalized to represent South Asia and the Middle East, respectively.
} 
Economists are fond of saying that there is no accounting for taste. But we believe Nordhaus and Boyer assume an implausibly intense public craving for heat. Other analysts have found more moderate, and to our tastes, more plausible temperature preferences. For example, a recent study explored the link between climate and subjective well-being across 67 countries, concluding that there is a statistically significant but weak relationship. Extrapolating from that relationship, the study found that the moderate anthropogenic changes in climate expected over the next 25 years will lead to increased happiness primarily in a handful of the coldest, northernmost countries; most of the world, including most developed countries, will already be unhappy with climate trends in the near future, long before a $2.5^{\circ} \mathrm{C}$ warming occurs (Rehdanz and Maddison 2005).

However, Nordhaus and Boyer assume a substantial willingness to pay for warmer weather. Following their disaggregated discussion of several categories of marketed and non-marketed impacts of climate change, they aggregate the results into a single damage function for modeling purposes:

$$
\mathrm{D}=-.0045 \mathrm{~T}+.0035 \mathrm{~T}^{2}
$$

Here D is global damages from warming, in trillions of 1995 dollars, and $\mathrm{T}$ is global mean temperature in degrees $\mathrm{C}$ above the 1900 level. (T was already at 0.4 by 1995.) The negative linear term in (2) makes damages negative, implying that there are net benefits from warming, whenever $\mathrm{T}$ is between 0 and about 1.3. This dip in the damage function results from the subjective evaluation of warming, since there are no other important sources of benefits from warming in the analysis.

Warming proceeds slowly at first, so that Nordhaus and Boyer project that it is on balance beneficial for the world through 2045, fully 50 years into their simulation. Those first 50 years are the ones that loom largest in their model, due to the effect of the high initial discount rate. By the time the temperature passes the $1.3^{\circ} \mathrm{C}$ mark and the model first shows net damages from warming, the discount factor, as we have seen, has reduced the present value of those damages to one sixth of their nominal value.

Our second modification to the model is designed to remove the hypothetical utility of moderate warming. We refer to this as $\mathrm{U}$, for utility modification. In order to make this change while avoiding new speculation about the unknown shape of the damage function, we simply drop the linear term, replacing the coefficient of -.0045 with 0 . That is, we use the damage function

$$
\mathrm{D}=.0035 \mathrm{~T}^{2}
$$

We believe that equation (3) has the correct general shape; it implies that climate damages are strictly positive and increasing more than proportionally to $\mathrm{T}$. In that sense, one could say that it is "less wrong" than (2), which implausibly implies a global net benefit from warming for the first 50 years of the simulation. However, this is not the same as claiming that we have precisely calibrated the damage function. We have not; indeed, we believe that such calibration is effectively impossible, a topic we return to in 
the conclusion. In particular, we have not revised the DICE treatment of the effect of temperature on the risk of a climate catastrophe, or the severity of such a catastrophe -one of the most important issues raised by recent research. We employ our modification U simply in order to examine the sensitivity of the model to these assumptions.

Nordhaus and Boyer are not the only economists to hypothesize a significant near-term benefit from global warming. Robert Mendelsohn and his colleagues calculate that there would be small net benefits, worldwide, from as much as a $3.5^{\circ}$ warming in 2100 (Mendelsohn et al. 2000). Their estimates are dominated by the assumed benefits to agriculture, which, in their view, can adapt rapidly to warmer conditions. Richard Tol, in another cost-benefit analysis, anticipates that agriculture can adapt to and benefit from a $2.5^{\circ}$ warming everywhere; he also estimates that moderate warming will produce a large net worldwide reduction in some types of temperature-related mortality (Tol 2002). Evaluation of these alternative hypotheses about benefits of warming is beyond the scope of this article; neither Mendelsohn et al. nor Tol explores the subjective valuation of warming that is so important in DICE.

\section{Updating climate science}

The analyses incorporated in the current DICE model were completed no later than 1999. In subsequent years, climate science has not stood still. William Cline, who also uses a modified version of the DICE model, has identified several specific, quantitative corrections in the modeling of the climate system that are needed to make DICE compatible with the analysis in the IPCC's 2001 report.

We have adopted two of Cline's climate modeling corrections, referring to them as $\mathrm{M}$, for modeling corrections, in the results presented below. One concerns non-carbon radiative forcing, i.e. the effects of greenhouse gases other than carbon dioxide. Cline argues that Nordhaus and Boyer have overstated the net cooling from sulfate aerosols, and that IPCC's 2001 scientific review implies that DICE's estimates for non-carbon radiative forcing should be increased. The second correction concerns the atmospheric retention of carbon dioxide; here Cline argues that DICE overstates the rate at which $\mathrm{CO} 2$ leaves the atmosphere for the biosphere and oceans. We document the precise changes we have made for modification $\mathrm{M}$ in our appendix, and refer the interested reader to (Cline 2004) for more discussion. For arguments that even greater changes are needed in the DICE treatment of climate science, see (Fisher 2003) and (Hall and Behl 2006).

No claim of completeness is being made for our short list of modifications. Many other aspects of climate dynamics are worthy of examination, but explicitly omitted here. For example, the objective of maximizing the total monetary value of global consumption (which is assumed in all of our scenarios) excludes the much-discussed question of equity-based weighting of outcomes. Likewise, we have not considered the important area of "socially contingent" impacts, reflecting society's responses to the environmental stresses caused by climate change (Downing 2005). We have not addressed the issues of modeling technological change and alternative energy sources. And we have not 
incorporated any "co-benefits" of climate mitigation strategies, such as the benefits of reducing other emissions from fossil fuel combustion, which accompany many $\mathrm{CO} 2$ reduction measures. Our goal is not to write the last word on possible modifications of DICE, but merely to study the sensitivity of the model to a limited spectrum of changes.

\section{Results}

To recap our modifications to the model, we have introduced:

- $\quad \mathrm{S}$, for social rate of time preference, setting the pure time preference component of the discount rate to zero;

- $\quad \mathrm{U}$, for utility modification, eliminating the hypothetical benefit of moderate warming; and

- $\quad \mathrm{M}$, for modeling corrections, changing DICE to make it more consistent with the IPCC analysis of 2001.

(We also made one small technical adjustment to all scenarios, changing an apparently arbitrary technique that DICE uses in the final years of its simulations. See the appendix for details.)

Thus there are eight possible scenarios, the NB scenario without any of our substantive modifications, and seven others including one or more modifications. The combination of all three of our modifications is scenario SUM; the order of the symbols is unimportant. To simplify the graphical presentation we omit scenarios U and SU from Figures 2-4, showing results for the other six combinations. (The omitted scenarios would fall quite close to scenarios $\mathrm{M}$ and SM, respectively, if shown in the graphs.)

Figure 2 shows the model's calculation of the carbon price in the six scenarios, expressed in 1995 dollars per metric ton of carbon. The carbon price is relatively low in $\mathrm{NB}$, especially at first, and only marginally higher in the other scenarios that use the same high discount rate, i.e. M and UM. The initial levels are \$6-\$16 for the three scenarios, rising, by 2195 , only to $\$ 138-\$ 165$. In contrast, the lower discount rates of scenario $\mathrm{S}$ lead to much higher and faster-growing carbon prices. And in the context of low discount rates, the other modifications have a larger impact. In the scenario combining all three modifications, SUM, the carbon price starts at \$197 and rises to \$579.

Although our scenarios present a broad range of carbon prices, they are well within the range of published estimates of the social cost of carbon (SCC): the initial price of \$6 from scenario NB is among the lowest published SCC figures, while the corresponding price of $\$ 197$ from scenario SUM is above average, but far from the top of the range, of SCC estimates (Downing 2005). 


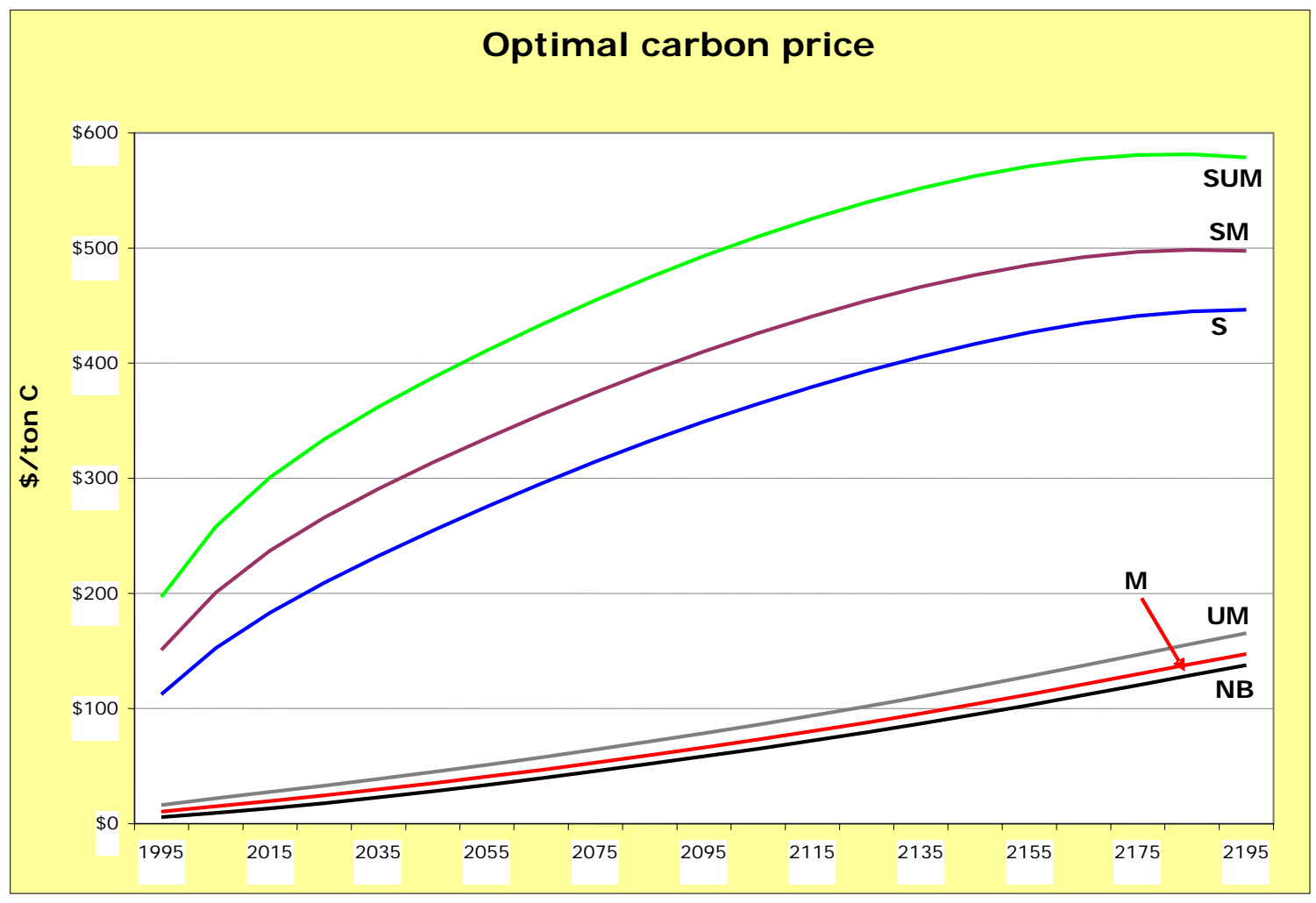

Figure 2

Figure 3 shows the reduction in global mean temperature achieved by the optimal carbon price in each scenario, compared to a business as usual baseline with no carbon policy. It is almost a mirror image of Figure 2. The high discount rate scenarios have very little effect on the temperature, with reductions in 2195 ranging from $0.19^{\circ}$ in NB to $0.25^{\circ}$ in scenario UM. The low discount rate alone, scenario S, results in a temperature reduction of $1.04^{\circ}$. And again, in the presence of low discount rates the other modifications make more of a difference: the temperature reduction in 2195 is $1.21^{\circ}$ in scenario SM, and $1.49^{\circ}$ in SUM.

In Figure 3, the temperature reduction caused by each scenario is measured relative to the business as usual scenario. Even in the highest-price scenarios considered here, temperatures are still rising, although more slowly than in the absence of the carbon price. In the two centuries covered by the graphs, the projected temperature rises to only $3^{\circ}$ above preindustrial levels in SUM, compared to $4.5^{\circ}$ under business as usual. And the temperature is projected to continue rising beyond 2195 in each of the scenarios. This is an "optimal" outcome in the terms defined by the economic model; it is not necessarily optimal in terms of scientific criteria or standards of sustainability. 


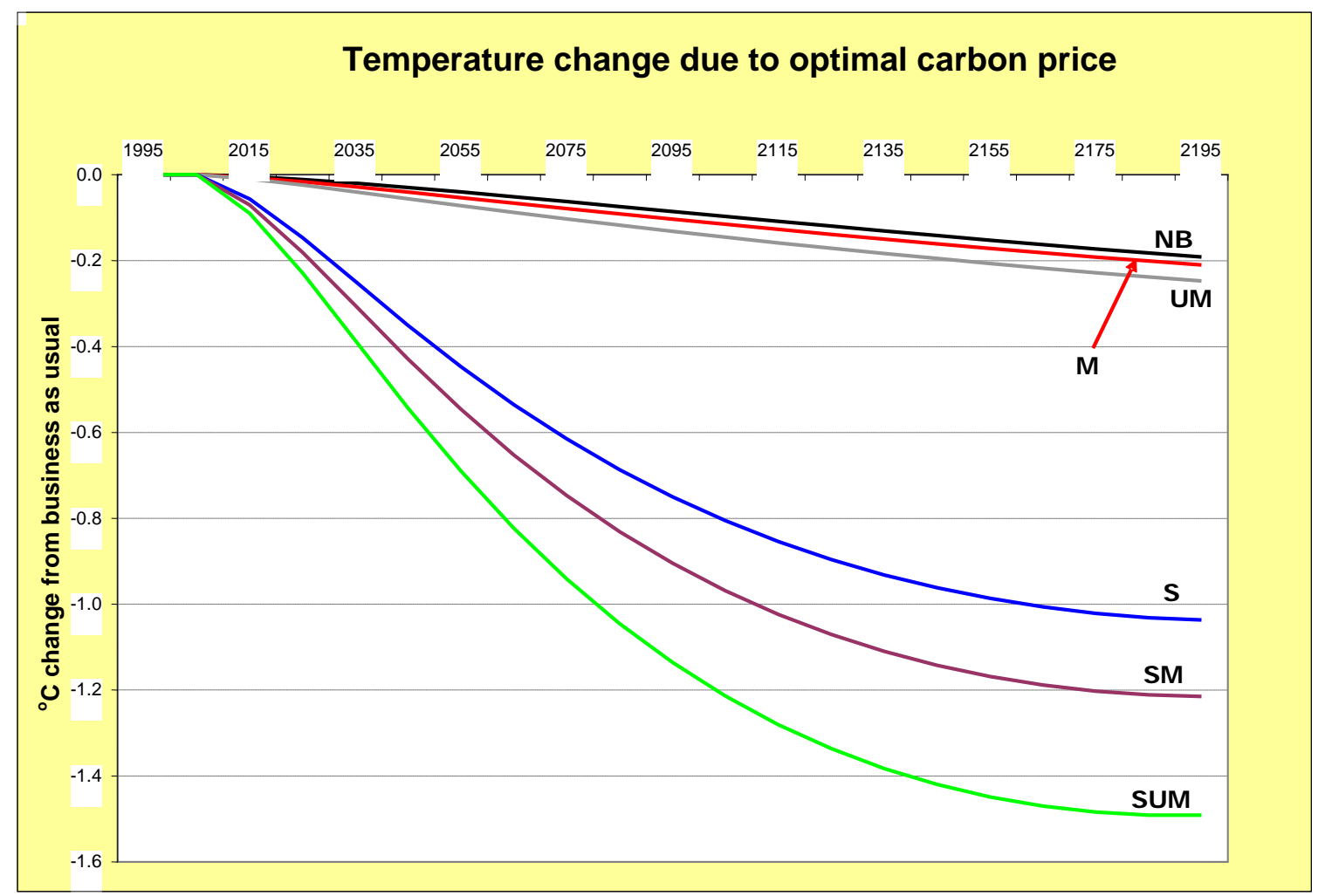

Figure 3

A final graph may shed some light on the dynamics of the model. Figure 4 shows the change in global consumption due to internalizing the optimal carbon price, compared to consumption levels in the business as usual baseline. The high discount rate scenarios, in which the optimal carbon price is comparatively low, show virtually no change in consumption in the 21 st century, followed by a modest increase in the 22 nd century -presumably because the slightly reduced temperature eventually leads to slightly reduced damages, and a corresponding boost to consumption.

The low discount rate scenarios, on the other hand, show a noticeable decrease in consumption throughout the 21 st century, followed by sizable increases beginning early in the 22nd century. Once again, modifications $U$ and $M$ appear to make more of a difference in the context of low discount rates. Our maximal modification, scenario SUM, projects a decrease in annual global consumption of $\$ 1$ trillion or more from 2015 to 2075. This is not a crippling blow -- in that scenario, total annual consumption is projected to grow from $\$ 26$ trillion to $\$ 56$ trillion over the same period -- but it does reflect a significant level of investment and sacrifice in the near term in exchange for much greater rewards later on. The change in consumption due to the carbon price turns positive for the first time in 2115. By 2195, SUM increases annual consumption by more than $\$ 4$ trillion. 


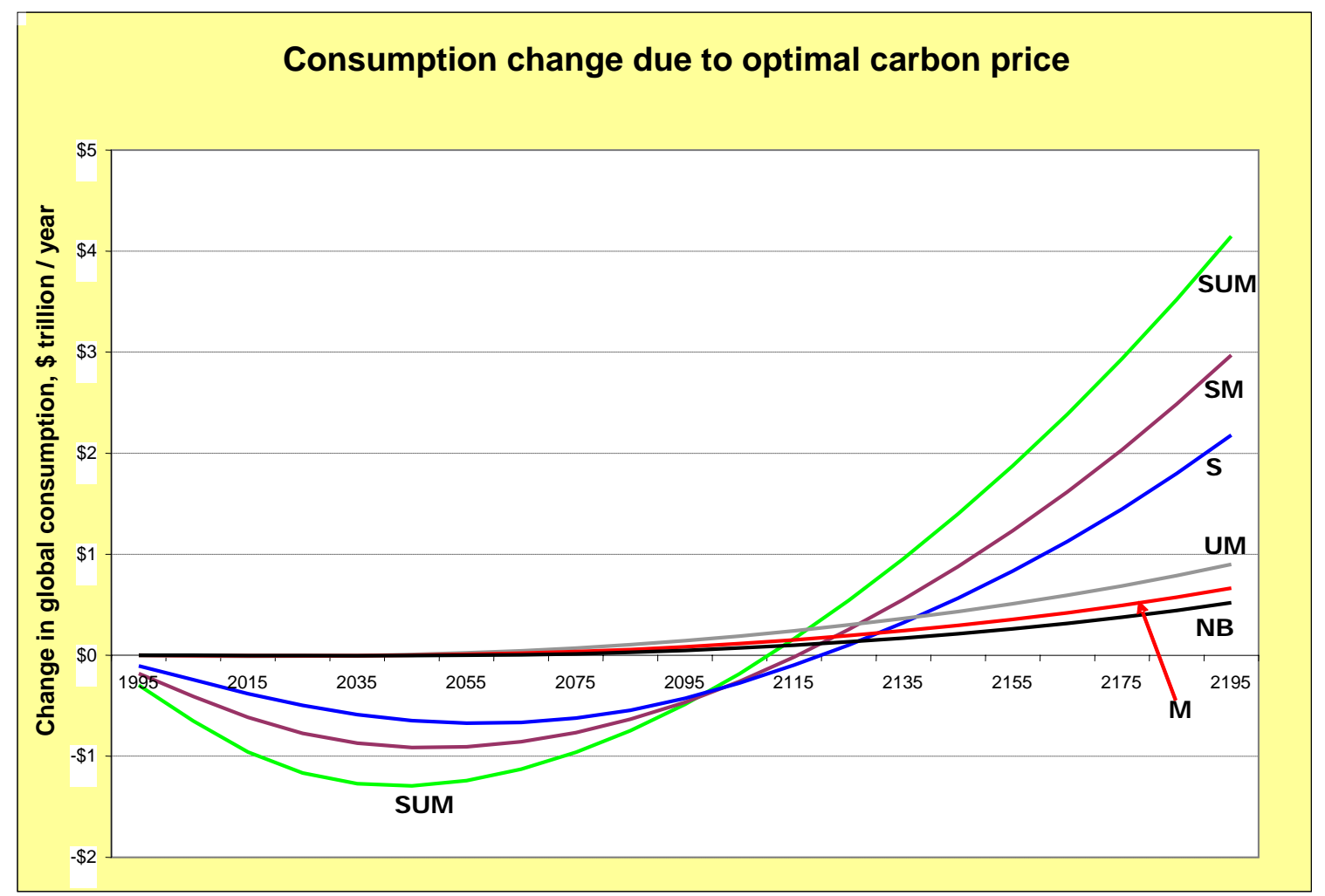

Figure 4

A further analysis of the scenario results, presented in Table 1, confirms the visual impression that $U$ and $M$ matter more in combination with $\mathrm{S}$ (i.e., at low discount rates). The first column of the table reports each scenario's optimal carbon price in 2195, as calculated by DICE.

The next three columns consider the "additive hypothesis": would the same results occur if the effects of $S, U$, and $M$ were independent and additive? Column 2 shows the increment in the optimal price for each single-factor scenario, relative to NB. For each of the multifactor scenarios, column 3 shows the carbon price that would be obtained by adding the price for NB plus the increments for each of the included factors. In the case of SUM, for instance, the additive hypothesis would combine the price for NB (\$138), plus the sum of the increments above that level for each of the three single factors $(\$ 10+\$ 21+\$ 309)$, for a total (including rounding error) of $\$ 477$. However, the optimal price for SUM is actually $\$ 579$; as column 4 shows, that is $21 \%$ greater than the amount implied by the additive hypothesis.

The final three columns consider the analogous "multiplicative hypothesis": would the same results occur if the effects of S, U, and M were independent and multiplicative? Here the effects of the single factor scenarios are expressed as ratios to the NB optimal price. The estimate for SUM under this hypothesis is the product of the NB result $(\$ 138)$, multiplied by the ratios for the three single factors $(1.070 * 1.149 *$ 
3.241), or \$549. Although this comes closer than the additive hypothesis, the actual estimate for SUM is still 5\% higher than the amount implied by the multiplicative hypothesis.

\begin{tabular}{|c|c|c|c|c|c|c|c|}
\hline & \multirow[b]{2}{*}{$\begin{array}{c}(1) \\
\text { optimal } \\
\text { price in } \\
2195\end{array}$} & \multicolumn{3}{|c|}{ Additive interactions } & \multicolumn{3}{|c|}{ Multiplicative interactions } \\
\hline & & $\begin{array}{c}(2) \\
\text { increment } \\
\text { over NB }\end{array}$ & $\begin{array}{c}(3) \\
N B+\text { sum } \\
\quad \text { of } \\
\text { increments }\end{array}$ & $\begin{array}{c}(4) \\
\text { ratio } \\
(1) /(3)\end{array}$ & $\begin{array}{l}\text { (5) } \\
\text { ratio to } \\
\text { NB }\end{array}$ & $\begin{array}{c}\text { (6) } \\
\text { NB * } \\
\text { product } \\
\text { of ratios }\end{array}$ & $\begin{array}{c}(7) \\
\text { ratio } \\
(1) /(6)\end{array}$ \\
\hline NB & $\$ 138$ & & & & & & \\
\hline M & $\$ 147$ & $\$ 10$ & & & 1.070 & & \\
\hline U & $\$ 158$ & $\$ 21$ & & & 1.149 & & \\
\hline UM & $\$ 165$ & & $\$ 168$ & 0.984 & & $\$ 169$ & 0.976 \\
\hline $\mathrm{S}$ & $\$ 446$ & $\$ 309$ & & & 3.241 & & \\
\hline SM & $\$ 498$ & & $\$ 456$ & 1.091 & & $\$ 478$ & 1.041 \\
\hline SU & $\$ 527$ & & $\$ 467$ & 1.129 & & $\$ 513$ & 1.028 \\
\hline SUM & $\$ 579$ & & $\$ 477$ & 1.214 & & $\$ 549$ & 1.054 \\
\hline
\end{tabular}

For the one multifactor scenario using high discount rates, UM, the optimal price is slightly below the level predicted by either the additive or the multiplicative hypothesis. It would not be far off to suggest that at high discount rates, $\mathrm{U}$ and $\mathrm{M}$ are independent and additive. But for all three multifactor scenarios using low discount rates, the optimal price is above the prediction of either hypothesis. This suggests that there is synergy between discount rates and the other factors we have considered; DICE responds nonlinearly to combinations of modifications, at least at low discount rates.

Turning to other non-economic indicators of climate impacts, our modifications have a substantial effect on the predicted atmospheric concentration of $\mathrm{CO} 2$. Each scenario has a different growth rate, and therefore a different rate of accumulation of $\mathrm{CO} 2$; in addition, the changes to climate modeling in our modification $\mathrm{M}$ imply higher atmospheric concentrations for any given growth rate. Atmospheric concentrations of $\mathrm{CO} 2$, for selected scenarios, are shown in Table 2.

\begin{tabular}{|lcccc|}
\hline \multicolumn{5}{|c|}{ Table 2. Atmospheric concentrations of CO2 } \\
\cline { 2 - 4 } & \multicolumn{3}{c|}{ parts per million (ppm) } & \\
Scenario & 1995 & \multicolumn{2}{c|}{2195} & 2195 \\
\cline { 3 - 4 } NB & & no C price & optimal price & \\
M & 350 & 778 & 730 & $6.2 \%$ \\
SUM & 350 & 856 & 798 & $6.8 \%$ \\
& 350 & 921 & 595 & $35.4 \%$ \\
\multicolumn{4}{l}{ Model outputs in gigatons (Gt) of carbon converted at $2.1 \mathrm{Gt}=1 \mathrm{ppm}$} \\
\hline
\end{tabular}


In the absence of a carbon policy, all of our DICE scenarios show CO2 concentrations more than doubling by 2195, relative to the 1995 base year, reaching dangerous levels of around $800-900 \mathrm{ppm}$. In the basic Nordhaus-Boyer scenario, the optimal carbon price reduces atmospheric $\mathrm{CO} 2$ by only about $6 \%$. Our scenario $\mathrm{M}$, with its modeling changes, implies faster growth of emissions, but has a similarly small percentage impact from the optimal price. In contrast, our scenario SUM implies even higher carbon concentrations in the absence of a carbon price, but the optimal price now reduces atmospheric carbon by more than one third. The level in 2195 is still $70 \%$ above 1995 , or roughly $600 \mathrm{ppm}$; the climate problem is by no means entirely solved by the carbon price in SUM. But the efficacy of the "optimal" price, perhaps as part of a broader mitigation strategy, is much more impressive.

A similar pattern can be seen in the maximum rate of change of temperature. Table 3 shows the fastest temperature increase in the first 200 years of each scenario (measured in degrees Celsius per decade, the basic unit of time in DICE). Again, scenario $\mathrm{M}$ makes the underlying problem look worse. And again, the optimal carbon price in either NB or M does very little. SUM does quite a bit more -- although not enough to eliminate the need for other policy initiatives.

\begin{tabular}{|c|c|c|c|}
\hline \multicolumn{4}{|c|}{ Table 3. Maximum rate of temperature change } \\
\hline \multirow[b]{2}{*}{ Scenario } & \multicolumn{2}{|c|}{$\begin{array}{l}\text { Maximum increase, 1995- } \\
2195 \text { (degrees /decade) }\end{array}$} & \multirow[t]{2}{*}{$\begin{array}{l}\% \text { reduction } \\
\text { due to } \mathrm{C} \text { price }\end{array}$} \\
\hline & no $\mathrm{C}$ price & optimal price & \\
\hline NB & .222 & .212 & $4.7 \%$ \\
\hline M & .304 & .297 & $2.2 \%$ \\
\hline SUM & .304 & .257 & $15.5 \%$ \\
\hline
\end{tabular}

\section{Conclusions}

This paper was motivated by a paradox: DICE, a well-known and important model, takes climate change seriously and analyzes its physical and economic causes and consequences in some detail, only to conclude that the optimal policy is to do almost nothing and cause almost no reduction in anticipated future warming. We found that this conclusion is traceable to a handful of modeling choices and assumptions: the use of a high initial discount rate; the assumption of large subjective benefits from moderate warming; and outdated technical parameters that understate the severity of the physical problem. Under these assumptions, the low optimal carbon price has only trivial impacts on physical indicators of climate change.

With minor changes to reflect different assumptions on these points, DICE finds that internalization of high and rising carbon prices is the optimal policy, leading to some decades of relative sacrifice (consumption is still rising during this period, just not as quickly as in the business as usual scenario) on behalf of much better future outcomes. In 
our alternative scenarios, the economic incentive due to the carbon price is not enough to solve the problem alone, but has a significant impact on atmospheric carbon concentrations and temperature changes. The discount rate appears to be the most important factor in our scenarios; however, this may simply reflect the relatively limited changes we made in the treatment of climate science and in the damage function. The importance of the other factors would be increased if we incorporated a greater probability of truly catastrophic outcomes with rising temperatures.

The focus on a group of changes is important because there are complex, nonlinear interactions among the various features of the model. Lower discount rates apparently make DICE more responsive to other modifications. Intuitively, at a high initial discount rate, the shape of the damage function 100 or more years from now hardly matters. If the subjective benefit of moderate warming is assumed to outweigh the damages from the first few decades of climate change, as is the case in DICE, then the cumulative present value of damages beyond that point is quite small, and the recommendation of only a modest carbon price is understandable. But at a lower discount rate, the model is more sensitive to assumptions about damages in the 22nd century and beyond. At least at low discount rates, DICE exhibits synergy between multiple modifications; its behavior cannot be understood by single-factor sensitivity analyses alone.

Lower discount rates not only change the optimal policy; they make long-run economic modeling inherently less precise. The farther we look into the future, the greater the uncertainties about the magnitude and timing of climate damages. Our alternative damage function, introduced in section 4, is, we believe, "less wrong" because it has a reasonable shape, eliminating the implausible net benefits of moderate warming; this is far from saying that we know it is right in any detail. Putting precise monetary values on uncertain damages that will occur hundreds of years from now has an air of unreality to it; we have not attempted to do so, and we are skeptical about attempts to do so in general. But the lower the discount rate, the more sensitive a model such as DICE becomes to the exact assumption about those uncertain, far-future damages -- and the wider the confidence interval becomes on the present value of future damages. Thus low discount rates make long-run economic modeling less predictively accurate, and so less useful in general.

If the appropriate discount rate is relatively low, implying wide uncertainty in the results of a multi-century model such as DICE, a humbler use of economic analysis might be preferable. The essence of the problem, which places such unbearable weight on decisions about discounting, is that the costs of an active climate policy typically occur long before the benefits. But this implies that, especially at a low discount rate, economic modeling is more reliable for the costs than for the benefits.

An alternative approach to economic modeling might therefore restrict itself to the better understood and shorter-term costs side of the equation. It might calculate the least-cost strategies for achieving a range of potential carbon reduction targets, and allow political processes to choose among them, based on society's collective willingness to pay 
for climate mitigation. Under this approach the claims of optimality would be gone, and with them the dilemmas that arise from assigning arbitrary prices to intrinsically priceless benefits (Ackerman and Heinzerling 2004). Instead, a rigorous economics of costeffectiveness would provide a transparently helpful menu of options for one of the world's most crucial public policy decisions.

Frank Ackerman is Director of the Research and Policy Program at the Global Development and Environment Institute, Tufts University; Ian J. Finlayson is the State Sustainability Program Manager for Massachusetts at the Executive Office of Environmental Affairs; inquiries can be directed to Frank.Ackerman@tufts.edu. 


\section{Appendix: Changes to the DICE model}

This appendix documents the precise changes we made to the DICE model, which we downloaded from Nordhaus' web site in early 2005. All cell references are to the Model sheet of the DICE99 Excel workbook.

\section{Model preparation changes}

1. Reducing end effects on capital: In the earlier years of the simulation, the model calculates the optimal investment level based on its effect on future years. This procedure becomes increasingly unviable toward the end of the simulation, so the model fixes the final year investment level at $2 \%$ of the capital stock. The $2 \%$ constraint appears to work smoothly for the low tax scenarios, but introduces illogical end effects in high tax scenarios, "pulling down" investment and mitigation effort in the final decades simply because the end of the simulation is approaching.

To minimize this problem, we fixed the final year investment at $7 \%$ of the capital stock. This reduces, although it does not entirely eliminate, the end effects in the high tax scenarios; it has virtually no effect on the low tax scenarios. Technically, we changed the formula in Cell AK77 from 0.02*AJ78 to 0.07*AJ78.

In addition, we report on only the first 200 years of the 340 years covered by DICE simulations. No qualitatively new, credible patterns appear after that point, while some of the scenarios begin to display artificial end effects in the third century. For this reason, the results reported in the text all end at 2195.

2. Streamlining macros to avoid continual resetting to default values: We edited the macros for BASE and for Optimal to remove the DefDam macro. This allows the model to retain changes for repeated runs, rather than resetting to the NB defaults prior to each use of the macros.

\section{Model assumption changes}

3. Modification $S$ - Social time preference for discounting: To eliminate the pure time preference term from the discount rate, we changed Cell B64 from 3 to 0, and Cell B65 from 0.257 to 0 . These cells are the initial value, and the rate of decline, respectively, of the pure time preference component of the discount rate.

4. Modification $U$ - Eliminating benefits of moderate warming: We changed Cell B5 from -.0045 to 0 . As explained in the text, this eliminates the (negative) linear term in the damage function, and thereby eliminates the net benefit from moderate warming.

5. Modification M - Climate model changes: The appendix to Cline 2004 describes a series of modifications to the DICE model. Here we adopt Cline's modifications C (noncarbon radiative forcing) and $\mathrm{G}$ (atmospheric retention), which were designed 
specifically to meet IPCC 2001 climate model assumptions. See (Cline 2004), pages 4041 , for more detailed explanation of these changes.

Non-carbon radiative forcing: DICE uses fixed, exogenous estimates for the influence of greenhouse gases other than carbon dioxide; Cline argues that they are too low. In both the original and Cline's version, the key parameter is constant from 2105 onward. The change occurs in Row 54, as follows:

$\begin{array}{lrrrrrrrrrrrr} & \mathbf{1 9 9 5} & \mathbf{2 0 0 5} & \mathbf{2 0 1 5} & \mathbf{2 0 2 5} & \mathbf{2 0 3 5} & \mathbf{2 0 4 5} & \mathbf{2 0 5 5} & \mathbf{2 0 6 5} & \mathbf{2 0 7 5} & \mathbf{2 0 8 5} & \mathbf{2 0 9 5} & \mathbf{2 1 0 5} \\ \text { N-B } & -0.197 & -0.062 & 0.073 & 0.207 & 0.342 & 0.477 & 0.611 & 0.746 & 0.881 & 1.015 & 1.15 & 1.15 \\ \text { Cline } & 0.670 & 0.742 & 0.814 & 0.885 & 0.957 & 1.029 & 1.101 & 1.173 & 1.245 & 1.316 & 1.388 & 1.46\end{array}$

Atmospheric retention: Cline argues that DICE understates the rate of retention of carbon dioxide in the atmosphere, and the rate of release of carbon dioxide from the biosphere and ocean into the atmosphere. To correct these understatements, we follow Cline in changing Cell B45 from 66.616 to 69, and Cell B46 from 27.607 to 30. Offsetting changes are required in Cell B47, from 33.384 to 31, and in Cell B48, from 60.897 to 58.5. 


\section{REFERENCES}

Ackerman, F. and L. Heinzerling (2004). Priceless: On Knowing the Price of Everything and the Value of Nothing. New York, The New Press.

Arrow, K. J. (1999). Discounting, morality, and gaming. Discounting and intergenerational equity. P. R. Portney and J. P. Weyant. Washington DC, Resources for the Future: 13-22.

Broome, J. (1992). Counting the cost of global warming. Cambridge, UK, White Horse Press.

Cline, W. R. (1992). The Economics of Global Warming. Washington DC, Institute of International Affairs.

Cline, W. R. (2004). Meeting the challenge of global warming. Global Crises, Global Solutions. B. Lomborg. New York, Cambridge University Press.

Dasgupta, P. (2001). Human Well-Being and the Natural Environment. Oxford, Oxford University Press.

Dasgupta , P., K.-G. Mäler and S. Barrett (1999). Intergenerational equity, social discount rates, and global warming. Discounting and Intergenerational Equity. P. R. Portney and J. P. Weyant. Washington, DC, Resources for the Future.

DeCanio, S. J. (2003). Economic Models of Climate Change: A Critique. New York, Palgrave Macmillan.

DeCanio, S. J. and P. Niemann (2006). "Equity effects of alternative assignments of global environmental rights." Ecological Economics 56: 546-559.

Downing, T. E., et al. (2005). Social Cost of Carbon: A Closer Look at Uncertainty. London, DEFRA: 90.

Fisher, A. C. (2003). Irreversibilities and catastrophic risks in climate change. Risk and Uncertainty in Environmental and Natural Resource Economics. J. Wesseler, H. Weikard and R. D. Weaver. Northampton, MA, Edward Elgar.

Frederick, S., G. Loewenstein and T. O'Donoghue (2002). "Time discounting and time preference: a critical review." Journal of Economic Literature 40(2): 351-401.

Ha-Duong, M. and N. Treich (2004). "Risk aversion, intergenerational equity and climate change." Environmental and Resource Economics 28: 195-207.

Hall, D. C. and R. J. Behl (2006). "Integrating economic analysis and the science of climate instability." Ecological Economics 57(3): 442-465. 
Heal, G. (1997). "Discounting and climate change." Climatic Change 37(2): 335-343.

Howarth, R. (2003). "Discounting and uncertainty in climate change policy analysis." Land Economics 79(3): 369-381.

Howarth, R. B. and R. B. Norgaard (1992). "Environmental valuation under sustainable development." American Economic Review 82: 473-477.

Joos, F., G. Müller-Fürstenberger and G. Stephan (1999). "Correcting the carbon cycle representation: how important is it for the economics of climate change?" Environmental Modeling and Assessment 4: 133-140.

Keller, K., B. M. Bolker and D. F. Bradford (2004). "Uncertain climate thresholds and optimal economic growth." Journal of the Environmental Economics in Management 48: 723-741.

Loomis, J. B. and D. S. White (1996). "Economic benefits of rare and endangered species: summary and meta-analysis." Ecological Economics 18(3): 197-206.

Manne, A. S. (1999). Equity, efficiency, and discounting. Discounting and intergenerational equity. P. R. Portney and J. P. Weyant. Washington DC, Resources for the Future: 111-130.

Mendelsohn, R., W. Morrison, M. E. Schlesinger and N. G. Andronova (2000). "Country-specific market impacts of climate change." Climatic Change 45: 553569.

Neumayer, E. (1999). "Global warming: discounting is not the issue, but substitutability is." Energy Policy 27: 33-43.

Newell, R. G. and W. A. Pizer (2004). "Uncertain discount rates in climate policy analysis." Energy Policy 32(4): 519-529.

Nordhaus, W. D. (1999). Discounting and public policies that affect the distant future. Discounting and intergenerational equity. P. R. Portney and J. P. Weyant. Washington DC, Resources for the Future: 145-162.

Nordhaus, W. D. and J. Boyer (2000). Warming the world: Economic models of global warming. Cambridge, Massachusetts, MIT Press.

Pearce, D., B. Groom, C. Hepburn and P. Koundouri (2003). "Valuing the future - recent advances in social discounting." World Economics 4(2): 121-141.

Ramsey, F. P. (1928). "A mathematical theory of saving." The Economic Journal 138(152): 543-59. 
Rehdanz, K. and D. Maddison (2005). "Climate and happiness." Ecological Economics 52: 111-125.

Schultz, P. A. and J. F. Kasting (1997). "Optimal reductions in CO2 emissions." Energy Policy 25(5): 491-500.

Tol, R. S. J. (2002). "Estimates of the damage costs of climate change." Environmental and Resource Economics 21: 47-73 and 135-160.

Watkiss, P., et al. (2005). The Social Costs of Carbon (SCC) Review - Methodological Approaches for Using SCC Estimates in Policy Assessment. London, DEFRA: 125.

Weitzman, M. L. (1998). "Why the far-distant future should be discounted at its lowest possible rate." Journal of Environmental Economics and Management 36(3): 201208. 
The Global Development And Environment Institute (GDAE) is a research institute at Tufts University dedicated to promoting a better understanding of how societies can pursue their economic goals in an environmentally and socially sustainable manner. GDAE pursues its mission through original research, policy work, publication projects, curriculum development, conferences, and other activities. The "GDAE Working Papers" series presents substantive work-in-progress by GDAE-affiliated researchers. We welcome your comments, either by e-mail directly to the author or to G-DAE,

Tufts University, 44 Teele Ave., Medford, MA 02155 USA; tel: 617-627-3530; fax: 617-627-2409; e-mail: gdae@tufts.edu; website: http://ase.tufts.edu/gdae.

\section{Papers in this Series:}

00-01 Still Dead After All These Years: Interpreting the Failure of General Equilibrium Theory (Frank Ackerman, November 1999)

00-02 Economics in Context: The Need for a New Textbook (Neva R. Goodwin, Oleg I. Ananyin, Frank Ackerman and Thomas E. Weisskopf, February 1997)

00-03 Trade Liberalization and Pollution Intensive Industries in Developing Countries: A Partial Equilibrium Approach (Kevin Gallagher and Frank Ackerman, January 2000)

00-04 Basic Principles of Sustainable Development (Jonathan M. Harris, June 2000)

00-05 Getting the Prices Wrong: The Limits of Market-Based Environmental Policy (Frank Ackerman and Kevin Gallagher, September 2000)

00-06 Telling Other Stories: Heterodox Critiques of Neoclassical Micro Principles Texts (Steve Cohn, August 2000)

00-07 Trade Liberalization and Industrial Pollution in Mexico: Lessons for the FTAA (Kevin Gallagher, October 2000) (Paper withdrawn- see www.ase.tufts.edu/gdae/ for details)

00-08 Waste in the Inner City: Asset or Assault? (Frank Ackerman and Sumreen Mirza, June 2000)

01-01 Civil Economy and Civilized Economics: Essentials for Sustainable Development (Neva Goodwin, January 2001)

01-02 Mixed Signals: Market Incentives, Recycling and the Price Spike of 1995. (Frank Ackerman and Kevin Gallagher, January 2001)

01-03 Community Control in a Global Economy: Lessons from Mexico’s Economic Integration Process (Tim Wise and Eliza Waters, February 2001)

01-04 Agriculture in a Global Perspective (Jonathan M. Harris, March 2001)

01-05 Better Principles: New Approaches to Teaching Introductory Economics (Neva R. Goodwin and Jonathan M. Harris, March 2001)

01-06 The \$6.1 Million Question (Frank Ackerman and Lisa Heinzerling, April 2002)

01-07 Dirt is in the Eye of the Beholder: The World Bank Air Pollution Intensities for Mexico (Francisco Aguayo, Kevin P. Gallagher, and Ana Citlalic González, July 2001)

01-08 Is NACEC a Model Trade and Environment Institution? Lessons from Mexican Industry (Kevin P. Gallagher, October 2001)

01-09 Macroeconomic Policy and Sustainability (Jonathan M. Harris, July 2001) 
02-01 Economic Analysis in Environmental Reviews of Trade Agreements: Assessing the North American Experience. (Kevin Gallagher, Frank Ackerman, Luke Ney, April 2002)

03-01 Read My Lips: More New Tax Cuts-The Distributional Impacts of Repealing Dividend Taxation (Brian Roach, February 2003)

03-02 Macroeconomics for the $21^{\text {st }}$ Century (Neva R. Goodwin, February 2003)

03-03 Reconciling Growth and the Environment (Jonathan M. Harris and Neva R. Goodwin, March 2003)

03-04 Current Economic Conditions in Myanmar and Options for Sustainable Growth (David Dapice, May 2003)

03-05 Economic Reform, Energy, and Development: The Case of Mexican Manufacturing (Francisco Aguayo and Kevin P. Gallagher, July 2003)

03-06 Free Trade, Corn, and the Environment: Environmental Impacts of US-Mexico Corn Trade Under NAFTA

03-07 Five Kinds of Capital: Useful Concepts for Sustainable Development (Neva R. Goodwin, September 2003)

03-08 International Trade and Air Pollution: The Economic Costs of Air Emissions from Waterborne Commerce Vessels in the United States (Kevin P. Gallagher and Robin Taylor, September 2003)

03-09 Costs of Preventable Childhood Illness: The Price We Pay for Pollution (Rachel Massey and Frank Ackerman, September 2003)

03-10 Progressive and Regressive Taxation in the United States: Who's Really Paying (and Not Paying) their Fair Share? (Brian Roach, October 2003)

03-11 Clocks, Creation, and Clarity: Insights on Ethics and Economics from a Feminist Perspective (Julie A. Nelson, October 2003)

04-01 Beyond Small-Is-Beautiful: A Buddhist and Feminist Analysis of Ethics and Business (Julie A. Nelson, January 2004)

04-02 The Paradox of Agricultural Subsidies: Measurement Issues, Agricultural Dumping, and Policy Reform (Timothy A. Wise, February 2004)

04-03 Is Economics a Natural Science? (Julie Nelson, March 2004)

05-01 The Shrinking Gains from Trade: A Critical Assessment of Doha Round Projections (Frank Ackerman, October 2005)

05-02 Understanding the Farm Problem: Six Common Errors in Presenting Farm Statistics (Timothy A. Wise, March 2005)

05-03 Securing Social Security: Sensitivity to Economic Assumptions and Analysis of Policy Options (Brian Roach and Frank Ackerman, May 2005)

05-04 Rationality and Humanity: A View from Feminist Economics (Julie A. Nelson, May 2005)

05-05 Teaching Ecological and Feminist Economics in the Principles Course (Julie A. Nelson and Neva Goodwin, June 2005)

05-06 Policy Space for Development in the WTO and Beyond: The Case of Intellectual Property Rights (Ken Shadlen, November 2005)

05-07 Identifying the Real Winners from U.S. Agricultural Policies (Timothy A. Wise, December 2005)

06-01 The Missing Links between Foreign Investment and Development: Lessons from Costa Rica and Mexico (Eva A. Paus and Kevin P. Gallagher, February 2006)

06-02 The Unbearable Lightness of Regulatory Costs (Frank Ackerman, February 2006) 
06-03 Feeding the Factory Farm: Implicit Subsidies to the Broiler Chicken Industry (Elanor Starmer, Aimee Witteman and Timothy A. Wise, June 2006)

06-04 Ethics and International Debt: A View from Feminist Economics (Julie A. Nelson, August 2006)

06-05 Can Climate Change Save Lives? (Frank Ackerman and Elizabeth Stanton, September 2006)

06-06 European Chemical Policy and the United States: The Impacts of REACH (Frank Ackerman, Elizabeth Stanton and Rachel Massey, September 2006)

06-07 The Economics of Inaction on Climate Change: A Sensitivity Analysis (Frank Ackerman and Ian J. Finlayson, October 2006) 